\title{
The Boston Alzheimer connection
}

\author{
Decoding Darkness: the Search for the Genetic Cause \\ of Alzheimer's disease \\ by Rudolph E. Tanzi and Ann B. Parson \\ Persueus Publishing · November 2000 \\ Hardback $£ 17 / \$ 26$
}

Edward Koo

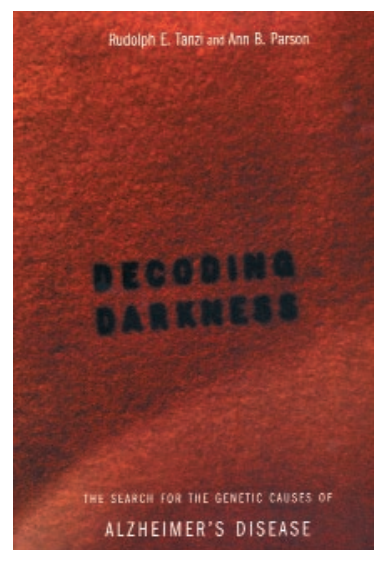

U ntil the 1970s, Alzheimer's disease (AD) was felt to be a rare neurodegenerative disorder of the pre-senile individual and not the most common age-associated dementing illness that is recognized today. One can divide the past 30 years of $\mathrm{AD}$ research into two periods: the "before cloning" research and the "after cloning"research.The refers to the amyloid precursor protein(APP), which was cloned in 1997 and began the molecular revolution of our understanding of AD. Several highly readable books on $\mathrm{AD}$ research have recently appeared. Dan Pollen in his wonderful book "Hannah's Heirs" (Oxford University Press, 1993) described a family originating from Russia with familial AD and documented the subsequent linkage of this family's disease gene to chromosome 14. A different approach was recently taken by Bob Katzman and Katherine Bick in "Alzheimer disease: the changing view" (Academic Press, 2000). Many of the investigators whose work laid the foundation of modern Alzheimer research in the "before cloning" era were interviewed and chronicled. The newest entry, "Decoding Darkness: The Search for the Genetic Causes of Alzheimer's Disease" by the Harvard neurogeneticist Rudolph Tanzi and the science writer Ann Parson takes a decidedly different approach.This book is, shall we say, a "Rudy-centric" view of the "after cloning" era of AD research, with more than a gracious nod to the late George Glenner. It was Glenner who in 1994 first published the partial sequence of the amyloid $\beta$-protein that opened the way to the subsequent cloning of the APP gene. In another irony of life, we learn from that book that Glenner passed away from another amyloid disease, not of his brain but of his body, in 1995.

This book is not meant to be comprehensive, nor does it represent an impartial view of $\mathrm{AD}$ research. Rather, it is the story of one of the key neurogeneticists involved in the hunt for the familial AD genes. The book begins with the young student, fresh from college, long hair and all, stumbling into the laboratory of another young investigator, James Gusella, at the Massachusetts General Hospital, Boston, USA. It was in this lab shortly thereafter that the first breakthrough of modern molecular genetics and neurodegenerative disease research occurred: the linkage of Huntington's disease locus to chromosome 4. This fortuitous encounter between budding student and junior scientist, however, led to and defined Tanzi's subsequent key roles in AD research and, in particular, the familial AD genes. Those who entered the field in the past decade may not know that Tanzi's trajectory to success in AD research occurred during his graduate school days. To make the young reader more envious, Tanzi even bypassed the now standard postdoctoral training period to establish his own laboratory. This book chronicles the period roughly from 1984 to 1999, and includes the cloning of the APP gene, linkage of the first families to chromosome 21, identification of the rare APP mutations, discovery of the presenilin-1 and -2 genes and ends with the recent efforts by pharmaceutical and biotech companies to treat this devastating disorder.

The book contains the bare basics of molecular genetics and Alzheimer biology, but I suspect that the casual reader will have difficulties following that aspect of the work. The book is fast-paced, exciting, a bit gossipy, fragmentary and contains a few errors of fact. Names of so many different investigators are mentioned along the way that I suspect an uninitiated reader will be lost at times. The book also leaves some interesting stories hanging. For example, how was it that Peter Hyslop initially found linkage in one of his families to chromosome 21 , only to discover four years later that the mutation resided within the newly discovered presenilin-1 gene? As in any highly competitive area, the Alzheimer field has it's share of paranoia and "tight-lipped" investigators. The authors relate an amusing story of Jerry Schellenberg from Seattle, who flew all the way to Italy with his data tucked in his shirt pocket, ready to announce to the world his finding about chromsome 14 linkage in case someone else did. However, as soon as he realized that no one else had similar data, he turned around and left the conference early.

This is an intensely personal book. It shares the successes but also the false starts and blind alleys that all researchers go through. In this book, as in many before, one witnesses the competitive world of academic research, the fiercely competitive scientists and what drives one particular investigator to this field. This odd assortment of interests is well summarized by a quote in the book: "[it's] a mixture of idealism, selfishness, generosity, greed, fun, anger, sex, drugs, and rock 'n' roll'.

Who should read this book? Alzheimer investigators will no doubt at times be amused and at times annoyed. It is a fun science detective story as long as the reader has some interest in AD. However, for this reviewer, it is a good read.

Edward Koo is at the University of California San Diego, La Jolla, CA 92093,

USA

email:edkoo@ucsd.edu

\section{Other Alzheimer's disease books}

Alzheimer's Disease-Current Treatments and Future Prospects by William Brown

FT Pharmaceuticals, $£ 475 / \$ 700$

Biological Markers in Dementia of Alzheimer's Type

edited by E. J. Fowler

Smith-Gordon and Company Ltd, £28/\$37

Pathology of Alzheimer's Disease edited by Alison Goate and F. Ashall Academic Press, £59.95/\$92

Alzheimer's Disease Reference by T. Reisberg

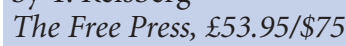

